\title{
INVESTIGATION ON THE EFFECT OF SLAG AND LIMESTONE POWDER ADDITION IN ALKALI ACTIVATED METAKAOLIN
}

\author{
X. Gao ${ }^{1}$, Q.L. Yu ${ }^{2}$, R. Yu ${ }^{3}$, H.J.H. Brouwers ${ }^{4}$, Z.H. Shui ${ }^{5}$ \\ ${ }^{1}$ Department of the Built Environment, Eindhoven University of Technology, P.O. Box 513, 5600 MB Eindhoven, the \\ Netherlands \\ ${ }^{2}$ Department of the Built Environment, Eindhoven University of Technology, P.O. Box 513, 5600 MB Eindhoven, the \\ Netherlands \\ ${ }^{3}$ Department of the Built Environment, Eindhoven University of Technology, P.O. Box 513, 5600 MB Eindhoven, the \\ Netherlands \\ ${ }^{4}$ Department of the Built Environment, Eindhoven University of Technology, P.O. Box 513, 5600 MB Eindhoven, the \\ Netherlands \\ ${ }^{5}$ State Key Laboratory of Silicate Materials for Architectures, Wuhan University of Technology, Wuhan Hubei 430070, \\ China
}

\begin{abstract}
Alkali activated material has recently attracted great attention as an environmentally friendly building material. Generally, it exhibits higher mechanical properties and better durability when compared with Portland cement based materials. In this article, mixed alkali activated systems consisting of $\mathrm{N}-\mathrm{A}-\mathrm{S}-\mathrm{H}$ and $\mathrm{C}-\mathrm{A}-\mathrm{S}-\mathrm{H}$ hydrated gels were produced, using metakaolin as a dominated starting material and granulated blast furnace slag as an additional calcium and silicate source. Limestone powder was then added into the blended metakaolin-slag system as a filler. The influences of slag and limestone powder on setting times, strength development and microstructure were analyzed. The results indicate that, with the increasing slag content, the setting time decreases; the compressive strength firstly increases and then decreases after the slag replacement exceeds a critical value. Additionally, an optimum content for limestone powder in the metakaolin-slag blends is around 15\%. The FTIR spectra and XRD pattern present the changes in reaction products when slag was added, and the scanning electron microscope results showed a denser matrix of the geopolymeric system when compared to reference sample. However, no significant changes of reaction products were detected when limestone powder was incorporated, which indicates that the limestone powder only works as a nonreactive phase in the alkali activated system.
\end{abstract}

Keywords: Alkali activation, Metakaolin, Slag, Limestone powder

\section{INTRODUCTION}

The production of Portland cement is now responsible for nearly $7 \%$ of the total $\mathrm{CO}_{2}$ emission around the world [1], other accompanied negative impacts of cement industry are the consumption of natural resources and high energy cost. Thus it is urgent to find approaches to reduce the environmental impacts of cement industry. Among those studies of finding alternatives to ordinary Portland cement, alkali activated materials have attracted great attention in recent years mainly due to their high mechanical properties, low environmental and energy consumptions [2,3]. Also other excellent properties are reported such as low heat resolution during hydration, fast early strength development, good durability related properties and thermal stability [4-7]. Raw materials used in producing alkali activated binders are usually industrial wastes, other than ordinary Portland cement, thus a promising future of sustainable development can be seen from this new clinker free building material.

Alkali activated materials are usually produced by mixing alkaline activator solutions with solid raw materials. The hydration process is called geopolymerization, which contains a series of chemical reactions including the dissolution of starting materials, polycondensation, condensation and finally the crystallization of new reaction products [8]. Final products can be classified into two types according to different raw material chemistry, for silicate and aluminum enriched precursors like metakaolin or fly ash, final products are amorphous alkaline aluminosilicate hydrate gels with a three-dimensional network of aluminate and silicate units that are charge balanced by alkali cations, or can be simply described as N-A-S-H type gel [9]; for calcium and silicate enriched ones like granulated blast furnace slag, final products are aluminium substituted C-S-H (I) type gel with lower $\mathrm{Ca} / \mathrm{Si}$ ratio [10]. Sodium hydroxide modified sodium silicate has been widely accepted as an ideal activator in terms of strength and other beneficial properties, the alkaline activator type and dosage have a significant influence on the reaction process and comprehensive properties of the final products [11]. Other important factors are curing conditions such as temperature, time, relative humidity and physicochemical properties of the starting materials such as mineralogical composition and fineness [12]. 
Commonly alkali activated materials based on $\mathrm{Si}$ and $\mathrm{Al}$ type have excellent mechanical properties, enhanced reinforcement steel bonding and fire resistance, but at the same time, drawbacks such as long setting time and slow strength development, high requirement of curing are obstacles to their practical application. Several researchers have found that adding slag into $\mathrm{Si}$ and $\mathrm{Al}$ based geopolymer can improve the compressive strength and decrease the setting time to some degree, also acceptable strength can be achieved [13,14]. Calcium component in slag is responsible for the decrease of setting, the stable coexistence of aluminum substituted C-S-H gel and the N-A-S-H gel contributes to the improvements in terms of strength, permeability and durability [15]. Besides, only a few work focuses on the utilization of limestone powder as additives in alkali activated systems. Limestone has already been used in Portland cement system successfully, the already known influences are improving workability and strength by the filler effect, accelerating the hydration process by the nuclear effect, also lowering the price and energy cost of the overall system. Thus there could be some potential benefits of using limestone in alkali activated systems such as modifying workability, strength, cost and environmental impact. The aims of this paper are to investigate the influences of slag on setting, strength and phase changes on alkali activated metakaolin, also to study the effects of limestone powder on metakaolin-slag blends.

\section{EXPERIMENTAL PROGRAM}

\subsection{Materials}

The metakaolin was produced in the laboratory by calcination of kaolinite under $750{ }^{\circ} \mathrm{C}$ for 4 hours. The kaolinite containing small amount of quartz and illite as impurities, mineral composition are shown in Table 1, with a specific surface area of $2230 \mathrm{~m}^{2} / \mathrm{kg}$ and more than $90 \%$ of particles are finer than $2 \mu \mathrm{m}$. The granulated blast furnace slag used has a specific surface area of $490 \mathrm{~m}^{2} / \mathrm{kg}$ and a specific density of $2.70 \mathrm{~g} / \mathrm{cm}^{3}$. Limestone powder with a $\mathrm{D}(0.5)$ of $5 \mu \mathrm{m}$ and specific surface area of $1100 \mathrm{~m}^{2} / \mathrm{kg}$ was used. The major chemical compositions of metakaolin, slag and limestone powder are given in Table 2.

Table 1: Mineral compositions of kaolinite

\begin{tabular}{|l|l|l|l|}
\hline Mineral & Kaolinite & Quartz & Illite \\
\hline$\%$ & 91.91 & 1.6 & 6.49 \\
\hline
\end{tabular}

Table 2: Major compositions of raw materials (\%)

\begin{tabular}{|l|l|l|l|}
\hline Oxides & Metakaolin & Slag & Limestone \\
\hline $\mathrm{CaO}$ & 0 & 38.06 & 53.42 \\
\hline $\mathrm{SiO}_{2}$ & 54.46 & 34.14 & 0.61 \\
\hline $\mathrm{Al}_{2} \mathrm{O}_{3}$ & 39.86 & 10.34 & 0.49 \\
\hline $\mathrm{MgO}$ & 0 & 7.95 & 1.62 \\
\hline $\mathrm{Fe}_{2} \mathrm{O}_{3}$ & 1.98 & 0.38 & 0.21 \\
\hline $\mathrm{LOI}$ & 2.01 & 0.03 & 43.15 \\
\hline
\end{tabular}

\subsection{Mix Design and Sample Preparation}

Samples were prepared by firstly mixing $\mathrm{NaOH}$ with sodium silicate solutions and then cooling it down to room temperature, then blending the liquid activator with the raw material in the mixer. Slag was added from $0 \%$ to $40 \%$ with a range of $10 \%$ by mass to study the influences of slag addition on setting, strength and reaction products of alkali activated metakaolin. For each sample, sodium hydroxide and sodium silicate were used with the fixed total $\mathrm{SiO}_{2} / \mathrm{Al}_{2} \mathrm{O}_{3}$ ratio of 4.0 and $\mathrm{Na}_{2} \mathrm{O} / \mathrm{Al}_{2} \mathrm{O}_{3}$ ratio of 1.0. Based on the alkali activated metakaolin-slag mixes with ideal property, limestone powder was added from $0 \%$ to $20 \%$ by mass of the total binder to analyze its effects on strength and reaction products of the blended system. A overall water/binder ratio of 0.37 was used for all mixes, while the total water includes the free water and water in activator solution, and the total binder was defined as raw materials and the solid phase in activator. All mixes were cured at $25 \pm 2{ }^{\circ} \mathrm{C}$ with a relative humidity of $90 \%$ until the testing age.

\subsection{Testing Methods}

The setting times of the alkali activated pastes were tested using the Vicat needle method in accordance with the Chinese national standard GB/T 1346-2011. The compressive strength testing were carried out according to the Chinese national standard GB/T 17671-2005. The samples were tested after 7 and 28 days curing, the strength values for each sample was obtained from the average of three mixes. The X-ray diffraction was conducted using a $\mathrm{CoK} \alpha$ radiation over the $2 \theta$ range from $5^{\circ}$ to $70^{\circ}$, a fourier transform infrared spectroscopy measurement with the wavenumbers ranging from 4000 to $400 \mathrm{~cm}^{-1}$ is performed to investigate the reaction products. All powder samples for XRD and FTIR analysis were prepared by mechanical grinding and tested after $28 \mathrm{~d}$ of curing. The microstructural characters of different mixes were investigated by a scanning electron microscope.

\section{RESULTS AND DISCUSSIONS}

\subsection{Setting Times}

The setting times of alkali activated metakaolin pastes with the slag replacement up to $40 \%$ are shown in Table 3. It can be seen that as the slag content increases, both the initial and final setting times decrease significantly. The initial setting time of the neat metakaolin sample was 155 mins, while as the slag replacement reached $40 \%$, the initial setting decreased nearly three times to 45 mins. Similar results happened to the final setting time. It seems that the remarkable reduction of setting times was caused by the calcium in the slag. The structure of metakaolin is dominated by silicate and aluminum oxide compounds, the Al-O and Si$\mathrm{O}$ bonds in metakaolin are relatively difficult to be activated due to the nature of the original clay-type structure, thus the initial and final setting times were relatively long. On the other hand, because of the presence of calcium in the molecular structure, the glassy phase of slag is more disordered, thus it is more vulnerable to breakdown under 
alkali activation. Finally, the fast release of calcium in solution lead to the reduced setting time.

Table 3: Setting times of metakaolin-slag blends

\begin{tabular}{|l|l|l|l|}
\hline $\begin{array}{l}\text { Metakaolin } \\
(\%)\end{array}$ & $\begin{array}{l}\text { Slag } \\
(\%)\end{array}$ & $\begin{array}{l}\text { Initial setting } \\
(\mathrm{min})\end{array}$ & $\begin{array}{l}\text { Final setting } \\
(\mathrm{min})\end{array}$ \\
\hline 100 & 0 & 155 & 240 \\
\hline 90 & 10 & 105 & 215 \\
\hline 80 & 20 & 70 & 165 \\
\hline 70 & 30 & 55 & 130 \\
\hline 60 & 40 & 45 & 115 \\
\hline
\end{tabular}

\subsection{Strength Development}

Figure 1 presents the $7 d$ and $28 d$ compressive strength results of alkali activated metakaolin with slag replacement from $0 \%$ to $40 \%$, which shows that as the slag content increases, the compressive strength firstly increases and reaches the highest value at the slag content of $20 \%$, then leads to a reduction of the compressive strength. All samples have a $7 \mathrm{~d}$ strength of more than $58 \mathrm{MPa}$ and $28 \mathrm{~d}$ strength of more than $60 \mathrm{MPa}$, and the highest strength reaches 72.5 $\mathrm{MPa}$ with $20 \%$ slag replacement by weight. Also, the strength development from $7 \mathrm{~d}$ to $28 \mathrm{~d}$ becomes more significant as the increase of slag content.

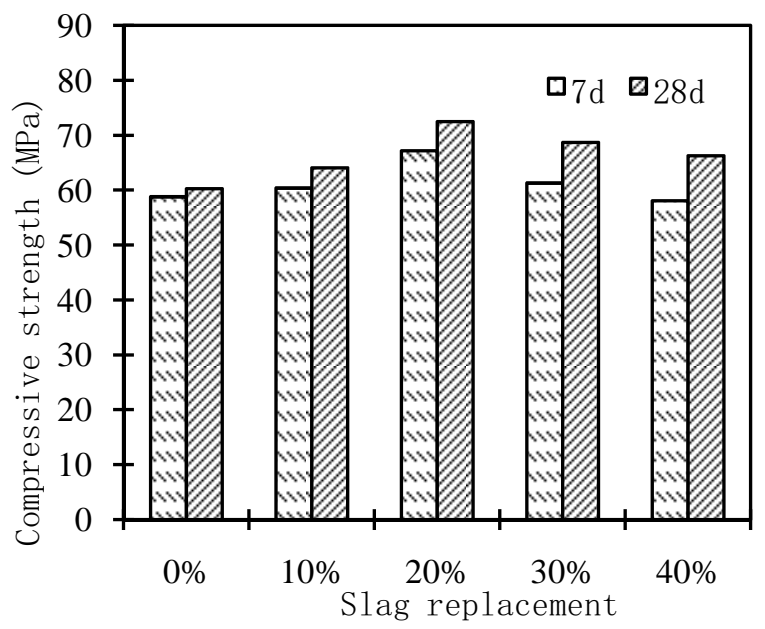

Fig. 1: Compressive strength of metakaolin-slag mixes

The increase in compressive strength when slag was added is attributed to the presence of the calcium in the slag and the accompanied formation of calcium enriched hydrated C-A-S$\mathrm{H}$ type gel is widely accepted as an gel that characterized of high strength [16]. The formation of small amount of C-A-S$\mathrm{H}$ gel helped to refine the microstructure of N-A-S-H gel (main hydration products of metakaolin) and generated more crosslinking within the reaction product [17], then resulted in an increase in compressive strength. The decreased strength when higher slag was added indicates that there may exist an ideal balance between the activator character and the raw materials.
Metakaolin and slag mixes that with the highest compressive strength results $(80 \%$ metakaolin and $20 \%$ slag in this case) were chosen and incorporated with limestone powder to study its effect on compressive strength of alkali activated metakaolin and slag blends, and the results are shown in Fig. 2. All samples show similar compressive strength values after $7 d$ curing except the one with $20 \%$ limestone content. The $28 \mathrm{~d}$ compressive strength stably increases as the limestone content increases, the highest strength is obtained with a limestone content of $15 \%$, the further higher content leads to a considerable reduction of compressive strength. This reveals that the addition of limestone powder has limited influence on the early strength but could slightly increase the strength at longer ages within the range of optimum content. Higher content of limestone powder may have detrimental effects on the structure of hydrated gels and then lead to the decrease of compressive strength.

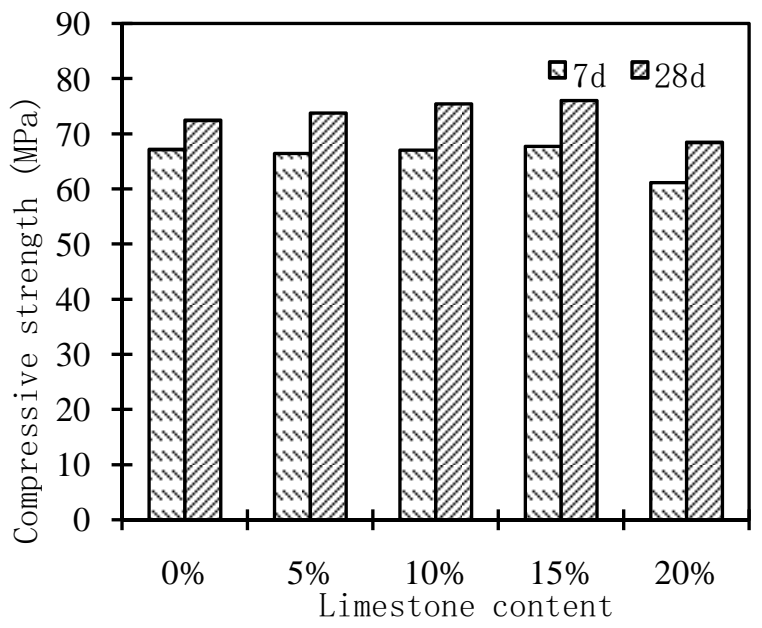

Fig. 2: Effect of limestone powder on metakaolin-slag mixes

\subsection{FTIR Spectra Analysis}

Figure 3 shows the fourier transform infrared spectra of alkali activated metakaolin paste samples after 28 days curing with slag contents of $0 \%, 20 \%$ and $40 \%$. The main absorption bands are listed in Table 4 . The major absorption band is around $1000 \mathrm{~cm}^{-1}$, which is assigned to the asymmetric stretching vibration of the $\mathrm{Si}-\mathrm{O}-\mathrm{T}(\mathrm{T}=\mathrm{Si}$ or $\mathrm{Al})$ bonds [18], a typical vibration band of N-A-S-H type gel from metakaolin. The presence of this band also indicates the polymerization process took place. With the incorporation of slag, the wavenumber of this band decreased. Generally, the reduction of wavenumber indicates the decrease of polymerization degree of the reaction products. Thus here it means the addition of slag into metakaolin reduced the polymerization degree of the hydrated gels to some extent, therefore the structure of the hydrated N-A-S-H gel was changed into a lower polymerization one by the presence of calcium from slag. It proves that the addition of slag indeed has some influences on the final hydrated product of metakaolin. Other significant wavenumber changes also reveal the structure of reaction products has been altered by the addition of slag, such as the bending vibration of T(IV)$\mathrm{O}$ at around $570 \mathrm{~cm}^{-1}$ disappeared as the slag was added and the T-O asymmetric stretching vibration bonds around 1400 
$\mathrm{cm}^{-1}$ increased at the beginning and then disappeared as the increase of slag content.

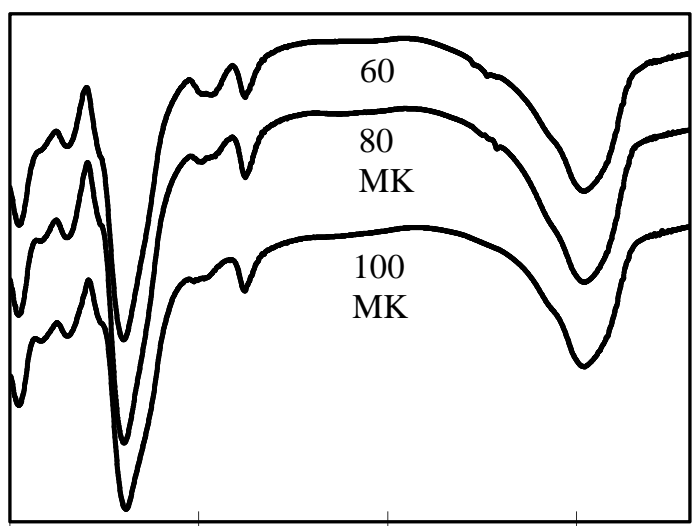

400

$$
1400 \text { Wavenumbers }\left(\mathrm{cm}^{-1}\right)^{3400}
$$

Fig. 3: FTIR spectra of metakaolin-slag blends

Table 4: Corresponding bands of metakaolin-slag blends

\begin{tabular}{|l|l|l|l|}
\hline $\begin{array}{l}\text { Absorption } \\
\text { bands }\end{array}$ & $\begin{array}{l}100 \mathrm{MK} \\
0 \text { GGBS }\end{array}$ & $\begin{array}{l}80 \mathrm{MK} \\
20 \mathrm{GGBS}\end{array}$ & $\begin{array}{l}60 \mathrm{MK} \\
40 \mathrm{GGBS}\end{array}$ \\
\hline$-\mathrm{OH}, \mathrm{H}_{2} \mathrm{O}$ & 3444 & 3445 & 3445 \\
\hline $\mathrm{H}_{2} \mathrm{O}$ & 1645 & 1647 & 1647 \\
\hline $\mathrm{O}-\mathrm{C}-\mathrm{O}$ & -- & -- & 1471 \\
\hline $\mathrm{T}-\mathrm{O}$ & 1375 & 1417 & -- \\
\hline $\mathrm{Si}-\mathrm{O}$ & 1015 & 1001 & 1000 \\
\hline $\mathrm{Al}(\mathrm{IV})-\mathrm{O}$ & 702 & 701 & 700 \\
\hline T(IV)-O & 566 & -- & -- \\
\hline $\mathrm{Si}-\mathrm{O}$ & 444 & 448 & 448 \\
\hline
\end{tabular}

The absorption bands at around $3450 \mathrm{~cm}^{-1}$ and $1650 \mathrm{~cm}^{-1}$ are attributed to the stretching and deformation vibrations of $\mathrm{O}-$ $\mathrm{H}$ and $\mathrm{H}-\mathrm{O}-\mathrm{H}$ groups, which present the water bonded in the reaction products. No significant changes in the bands at around $700 \mathrm{~cm}^{-1}$, which represent the vibration of four coordinated aluminum mainly from metakaolin, showing that the addition of slag has limited influence on the structure of $\mathrm{AlO}_{4}$ in the final reaction products. The absorption bands around $450 \mathrm{~cm}^{-1}$ represent the internal deformation vibrations of $\mathrm{Si}-\mathrm{O}$ bonds [19], which is mainly influenced by the nature of raw materials and thus no remarkable changes take place. The absorption band around $1470 \mathrm{~cm}^{-1}$ appeared only in the samples with large slag content, it represents the asymmetric stretching mode of the $\mathrm{O}-\mathrm{C}-\mathrm{O}$ groups [20], which means the carbonation has taken place to some extent, it may also indicate that samples with higher slag content are more vulnerable to carbonation, but still more study are needed to confirm this conclusion. The infrared spectra of samples containing limestone powder are not shown because there are no significant changes in the major absorption bands when limestone powder was added, which indicates that the incorporation of limestone powder has no influence on the reaction products and it only works as an non-reactive filler in alkali activated system.

\subsection{XRD Analysis}

The XRD patterns of alkali activated metakaolin pastes with $0 \%, 20 \%$ and $40 \%$ slag replacement are shown in Figure 4. The main reaction products of all mixes are amorphous phases except small amount of crystalline phases that obtained from the raw materials such as quartz and illite. The major hump area for neat metakaolin samples are from $20^{\circ}$ to $30^{\circ}$, which is within the typical range of alkali activated metakaolin and reveals the formation of hydrated N-A-S-H type gels from metakaolin. The amorphous phases with humps ranging from $20^{\circ}$ to $30^{\circ}$ can be regarded as the result of the geopolymerization progress of metakaolin.

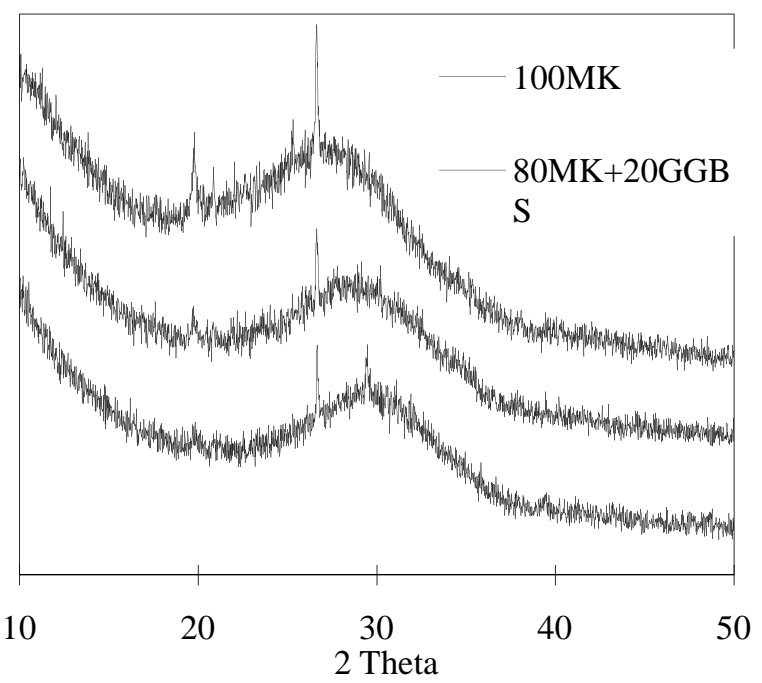

Fig. 4: XRD spectra of metakaolin-slag blends

As the slag content increases, the main hump area gradually moves to higher degree, which is in coordiance with the FTIR results and reveals the phase changes in reaction products caused by slag addition. As the slag content continues to increase, the intensity peaks at around $30^{\circ}$ appeares, which represents the formation of an C-S-H type gel from alkali activated slag. The intensity peaks that represent $\mathrm{C}-\mathrm{S}-\mathrm{H}$ gel becomes more significant in samples with higher slag content. Combined with the results from FTIR, the available calcium in the solution caused by the addition of slag seems to have significant influences on the reaction products of silicate and aluminum dominated alkali activated metakaolin, causing the formation of reaction products other than N-A-S-H and changing the original N-A$\mathrm{S}-\mathrm{H}$ gel structure to some extent such as a lower polymerization degree and changing the major hump areas. The XRD patterns with limestone powder incorporation are not shown because as the limestone content increases in the metakaolin and slag mixes, no changes take place in the original hump areas and intensity peaks, the intensity peaks of limestone still remain unchanged, which combined with the FTIR result reveals again that the limestone powder seems to work as only a filler in the alkali activated system. 


\subsection{SEM Analysis}

The SEM images of the $28 \mathrm{~d}$ alkali activated metakaolin paste samples containing $0 \%$ and $20 \%$ slag are shown in Figure 5. The left and right column represents the neat metakaolin sample and samples containing $20 \%$ slag, respectively.
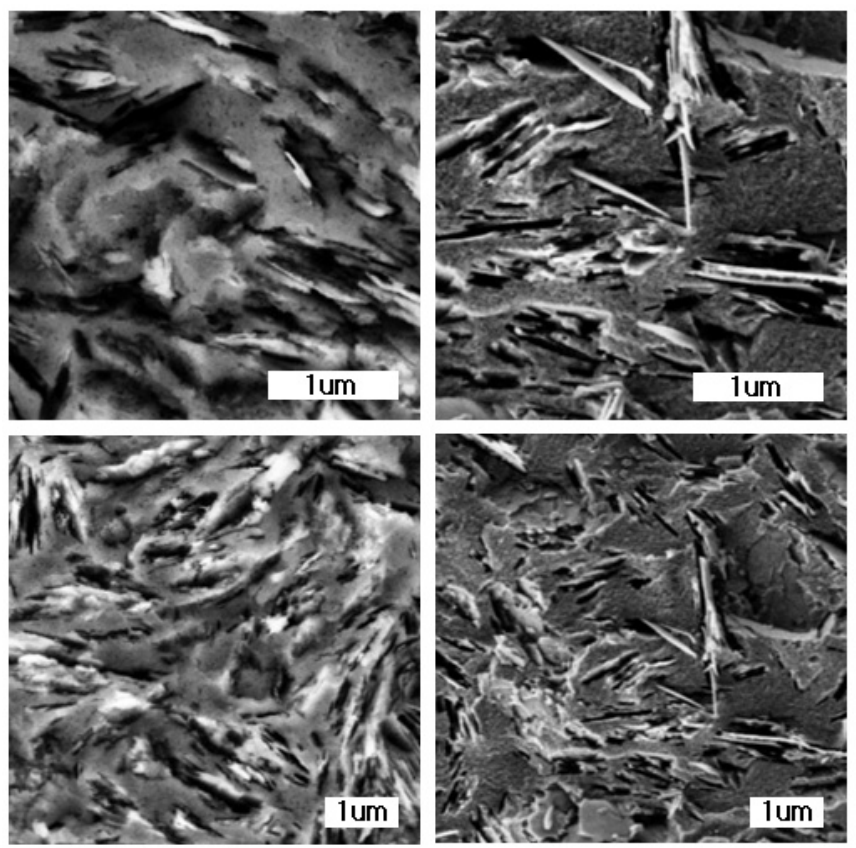

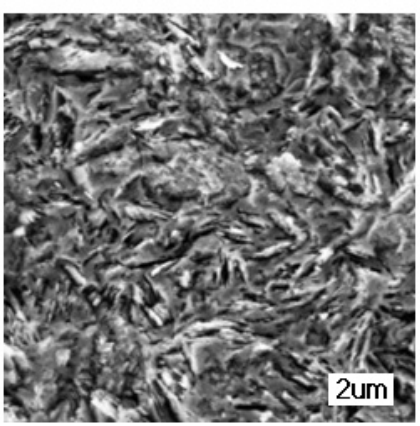

AA-MK

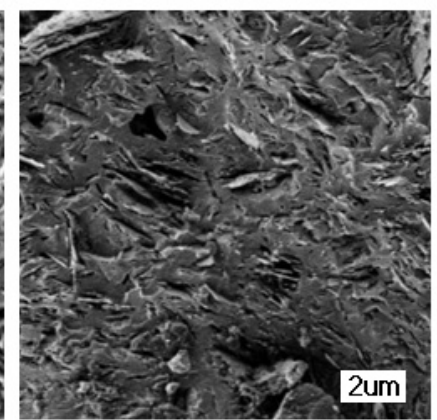

AA-MK/GGBS
Fig. 5: SEM images of metakaolin with/without slag addition

It can be seen that even though neat alkali activated metakaolin samples have acceptable $28 \mathrm{~d}$ compressive strength of around $60 \mathrm{MPa}$, some remarkable pores are still remaining under high magnifications. The reaction products exhibit layered structure in short ranges and disordered in longer ranges. The failure of samples in compressive strength test also showed layered structure, it seems that the nature of clay-type structure of metakaolin should be responsible for the failure. When a suitable content of slag was added, pores between the layers of alkali activated metakaolin were condensed by the hydrated slags. Also, the addition of slag provides calcium and leads to the formation of C-S-H type gel, which is characterized by a high strength, linked together with the original N-A-S-H gel, then contributes to the refinement of microstructure and improves the compressive strength.

\section{CONCLUSION}

The incorporation of slag significantly reduced the initial and final setting times of alkali activated metakaolin, and the setting times continually decreased as the increase of the slag content. The compressive strength firstly increased and then decreased as the slag content increased, and the optimum slag content in this case is $20 \%$, similar results were obtained in limestone powder addition into metakaolin-slag blends and the optimum limestone powder content is around $15 \%$. Both the XRD and FTIR results show significant changes in reaction products as a result of slag incorporation. Both $\mathrm{N}-\mathrm{A}-$ $\mathrm{S}-\mathrm{H}$ from metakaolin and $\mathrm{C}-\mathrm{S}-\mathrm{H}$ type gel from slag were detected, the addition of slag induced some changes of the original N-A-S-H gel structure such as the polymerization degree and the disappearance of some typical vibration bonds. Limestone powder seemed to work as an non-reactive filler in the alkali activated system since no significant changes were detected in both XRD and FTIR analysis. The microstructure analysis showed that the original alkali activated metakaolin paste was modified by the addition of slag, resulting in a denser matrix and resulted in an improved compressive strength.

\section{REFERENCES}

[1]. Alaa M. Rashad. A comprehensive overview about the influence of different additives on the properties of alkaliactivated slag - A guide for Civil Engineer. Construction and Building Materials, 2013; 47: 29-55.

[2]. Fernando Pacheco, Joao Castro-Gomes, Said Jalali. Alkali-activated binders: A review. Part1: Historical background, terminology, reaction mechanisms and hydration products. Construction and Building Materials, 2008; 22: 1305-1314.

[3]. Weil M, Dombrowski K, Buchawald A. Life-cycle analysis of geopolymers. In: Provis J. Van Deventer J, editors. Geopolymers, structure, processing, properties and applications. Cambridge, UK: Woodhead Publishing Limited; 2009; 194-210. ISBN-13: 97818456914494.

[4]. Shi C, Krivenko PV, Roy D. Alkali-activated cements and concretes. USA and Canada: Taylor and Francis; 2006.

[5]. Chen W, Brouwers H.J.H. The hydration of slag. Part 1: Reaction models for alkali-activated slag. Journal of Materials Science, 2007; 42: 428-443.

[6]. Bakharev T, Sanjayan JG, Cheng Y-B. Resistance of alkali-activated slag concrete to acid attack. Cement and Concrete Research, 2003; 33:1607-1611.

[7]. Rashad AM, Bai Y, Basheer PAM, Collier NC, Milestone NB. Chemical and mechanical stability of sodium sulfate activated slag after exposure to elevated temperature. Cement and Concrete Research, 2012; 42: 333-343.

[8]. Caijun Shi, Fernández Jiménez, Angel Palomo. New cements for the 21st century: The pursuit of an alternative to Portland cement. Cement and Concrete Research, 2011; 41: 750-763.

[9]. M.L. Granizo, S. Alonso, M.T. Blanco-Varela, A. Palomo, Alkaline activation of metakaolin: effect of calcium hydroxide in the products of reaction, Journal of the American Ceramic Society, 2002; 85: 225-231. 
[10]. S.D. Wang, K.L. Scrivener, ${ }^{29} \mathrm{Si}$ and ${ }^{27} \mathrm{Al}$ NMR study of alkali-activated slag. Cement and Concrete Research, 2003; 33: 769-774.

[11]. Alexandre Silva, et al. The effects of $\mathrm{Na}_{2} \mathrm{O} / \mathrm{SiO}_{2}$ molar ratio, curing temperature and age on compressive strength, morphology and microstructure of alkali-activated fly ashbased geopolymers. Cement and Concrete Composites, 2011; 33: 653-660.

[12]. A.R. Brough, A. Atkinson. Sodium silicate-based, alkali-activated slag mortars: Part I. Strength, hydration and microstructure. Cement and Concrete Research, 2002; 32: 865-879.

[13]. Susan A. Bernal, Erich D. Rodriguez, Ruby Mejia de Gutierrez, Marisol Gordillo, John L. Provis. Mechanical and thermal characterisation of geopolymers based on silicateactivated metakaolin/slag blends. Journal of Materials Science, 2011; 46: 5477-5486.

[14]. Susan A. Bernal, Ruby Mejia de Gutierrez, John L. Provis. Engineering and durability properties of concretes based on alkali-activated granulated blast furnace slag metakaolin blends. Construction and Building Materials, 2012; 33: 99-108.

[15]. Zhang Zuhua, Yao Xiao, Zhu Huajun. Potential application of geopolymers as protection coatings for marine concrete: II. Microstructure and anticorrosion mechanism. Applied Clay Science, 2010; 49: 7-12.

[16] .Shao-Dong Wang, Karen L. Scrivener. Factors affecting the strength of alkali activated slag. Cement and Concrete Research, 1994; 24: 1033-1043.

[17]. Susan A. Bernal, John L. Provis, et al. Evolution of binder structure in sodium silicate-activated slag-metakaolin blends. Cement and Concrete Composites, 2011; 33: 46-54.

[18]. M. Criado, A. Fernandez-Jimenez, A. Palomo. Alkali activation of fly ash: Effect of the $\mathrm{SiO}_{2} / \mathrm{Na}_{2} \mathrm{O}$ ratio Part I: FTIR study. Microporous and Mesoporous Materials, 2007; 106: 180-191.

[19]. M. Criado, A. Fernandez-Jimenez, A. Palomo. Alkali activation of fly ashes. Part 1: Effect of curing conditions on the carbonation of the reaction products. Fuel, 2005; 84: 2048-2054.

[20]. Isabella Lancellotti, et al. Inorganic polymers from alkali activation of metakaolin: Effect of setting and curing on structure. Journal of Solid State Chemistry, 2013;200: 341-348.

\section{BIOGRAPHIES}

Xu Gao, has received his Master's degree from Wuhan University of Technology, China. Currently working as a Ph.D. student in the Department of the Built Environment, Eindhoven University of Technology, the Netherlands. His research interests include the modification, modeling and application of alkali activated mateirals.

Qingliang Yu, received his Ph.D. degree from Eindhoven University of Technology, the Netherlands. He is currently working as an assistant professor in the Department of the Built Environment, Eindhoven University of Technology. His research interests include lightweight aggregate concrete, air purring functional concrete and gypsum based concrete.
Rui Yu, has received his masters from Wuhan University of Technology, China. Currently achieving an Ph.D. degree in the department of the Built Environment, Eindhoven University of Technology, the Netherlands. His research interests include the ultra-high performance concrete and fiber reinforced concrete.

H.J.H. Brouwers, is professor Building Materials and head of the unit Building Physics \& Services at Eindhoven University of Technology.

Zhonghe Shui, has received his Ph.D. degree in 2001 from Delft University of Technology, The Netherlands. He is currently working in Wuhan University of Technology, China as a full professor in the Department of Material Science. 